\title{
Surface topography of Dome Concordia (Antarctica) from kinematic interferential GPS and bedrock topography
}

\author{
A. Capra, ${ }^{1}$ R. Gefalo,${ }^{2}$ S. Gandolfi, ${ }^{1}$ G. Manzoni,${ }^{2}$ I. E. Tabacco, ${ }^{3}$ L. Vittuari ${ }^{1}$ \\ ${ }^{1}$ Department of Structural, Transport, Water, Surveying and Territorial Engineering (DISTART), University of Bologna, I-40136 Bologna, Italy \\ ${ }^{2}$ Department of Civil Engineering, University of Trieste, I-34127 Trieste, Italy \\ ${ }^{3}$ Division of Geophysics, Department of Earth Sciences, University of Milano, I-20129 Milano, Italy
}

\begin{abstract}
A new plano-altimetric map of the Dome Concordia (Dome C) area was drawn up from 1995/96 kinematic double-frequency global-positioning-system (GPS) data of two different projects, as well as static GPS data from a geodetic net for deformation analysis and ice-flow velocity measurements covering an area of about $2000 \mathrm{~km}^{2}$.

The GPS surveys were carried out for EPICA during the 10th and 1lth Italian Expeditions to choose the optimal location for deep ice-core drilling at Dome C. The accuracy of the kinematic survey was tested by analysing the height-value differences at intersections between different profiles; values ranged from 50-150 $\mathrm{mm}$.

The new map was compared with the 1993 kinematic interferential GPS data and residuals between the 1993 and 1995 data were calculated. The surface topographic values were used to calculate the elevation of the Dome $\mathrm{C}$ area bedrock, obtained from the reference ground-based and airborne radio-echo-sounding surveys.
\end{abstract}

\section{INTRODUGTION}

GPS kinematic and static measurements and radio-echosounding (RES) surveys were carried out in the framework of the European Project on Ice Coring in Antarctica (EPICA), Dome Concordia (Dome G) project, in order to examine the glacier dynamics thoroughly. As ice flow is related not only to the ice properties but also to ice thickness and bedrock slope, a precise surface morphology is needed to detect the ice divide and the main ice-flow directions.

During the 1993 Dome C French-Italian Antarctic campaign, an initial kinematic global-positioning-system (GPS) survey was performed using two geodetic Ll frequency Trimble 4000SE GPS receivers. The GPS surveys evaluated height variations over a $1500 \mathrm{~km}^{2}$ area, in order to localize the topographic dome where the $4 \mathrm{~km}$ drilling was to be undertaken.

A morphological map, obtained from radar-altimeter data (Brisset and Rémy, 1996) was first used to localize a position on Dome C $\left(75^{\circ} 09^{\prime} \mathrm{S} ; 123^{\circ} 06^{\prime} \mathrm{E}\right)$. In summer 1993 , a French DORIS (Détermination d'Orbite et Radiopositionnement Intégrés par Satellite) antenna was installed at this location (Vincent, 1994) to obtain the absolute geographic coordinates with an accuracy better than $0.10 \mathrm{~m}$ (World Geodetic System WGS84 coordinates: $75^{\circ} 09^{\prime} 09.8794^{\prime \prime} \mathrm{S}, 123^{\circ} 05^{\prime}$ $55.2725^{\prime \prime} \mathrm{E} ; 3232.772 \mathrm{~m}$ a.s.l.). The first base station for the kinematic GPS survey was near the DORIS antenna, at the above location. A second GPS receiver, mounted on a snow tractor (Challenger DV87), was used as a rover. GPS survey profiles were star-shaped, centered on this position (Fig. 1).

The integration of the carrier-phase data with radar-altimetric data from the European Remote-Sensing Satellite (ERS-1) (performed by F. Rémy, Groupe de Recherche de Géodésie Spatiale, Tolouse) provided coordinates of the maximum elevation site for the subsequent topographic and geophysical surveys (Cefalo and others, 1996). The resulting location (Table 1 ) is approximately $11 \mathrm{~km}$ northeast of the initial Dome $\mathrm{C}$ position.

\section{RES AND GPS SURVEYS IN 1995/96}

Kinematic GPS and RES surveys were carried out during the 1995/96 Antarctic campaign to investigate the topographic surface and bedrock topography. A star-shaped grid, centered on the new Dome C location (kinematic survey A, Fig. 1), was surveyed in conjunction with a ground RES survey (Tabacco and others, 1998). Other kinematic GPS profiles, covering an area of about $2000 \mathrm{~km}^{2}$ (Gandolfi and Vittuari, 1996) (kinematic survey B, Fig. 1), were also carried out.

Sixty $\mathrm{MHz}$ airborne and ground-based radar measurements were made on three grids. The first, a $80 \mathrm{~km} \times 120 \mathrm{~km}$ rectangular grid with $10 \mathrm{~km}$ spacing between flight lines, was centred on the summit point, with the longer side parallel to the apparent dome axis. The second, a $50 \mathrm{~km} \times 50 \mathrm{~km}$ square grid with $10 \mathrm{~km}$ line spacing, was concentric with the previous one, but shifted by $5 \mathrm{~km}$ from the lines of the "big grid" in order to obtain a final coverage in the central part of the area with a spacing of $5 \mathrm{~km}$ between the flight lines. The third, ground-based survey, was made up of six right-angled isosceles triangles, with the perpendicular lines $10 \mathrm{~km}$ long, rotated from each other by $60^{\circ}$. The total airborne survey

Table 1. Elipsoid and plane UTM coordinates of Dome C obtained from the analysis of the 1993 kinematic GPS data

WGS84 geographic coordinates

$$
\begin{array}{cc}
\phi=75^{\circ} 06^{\prime} 06.35^{\prime \prime} \mathrm{S} & \lambda=123^{\circ} 23^{\prime} 42.76^{\prime \prime} \mathrm{E} \\
\text { Plane UTM coordinates } & \\
\mathrm{E}=511344.43 \mathrm{~m} & \mathrm{~N}=1664998.83 \mathrm{~m}
\end{array}
$$




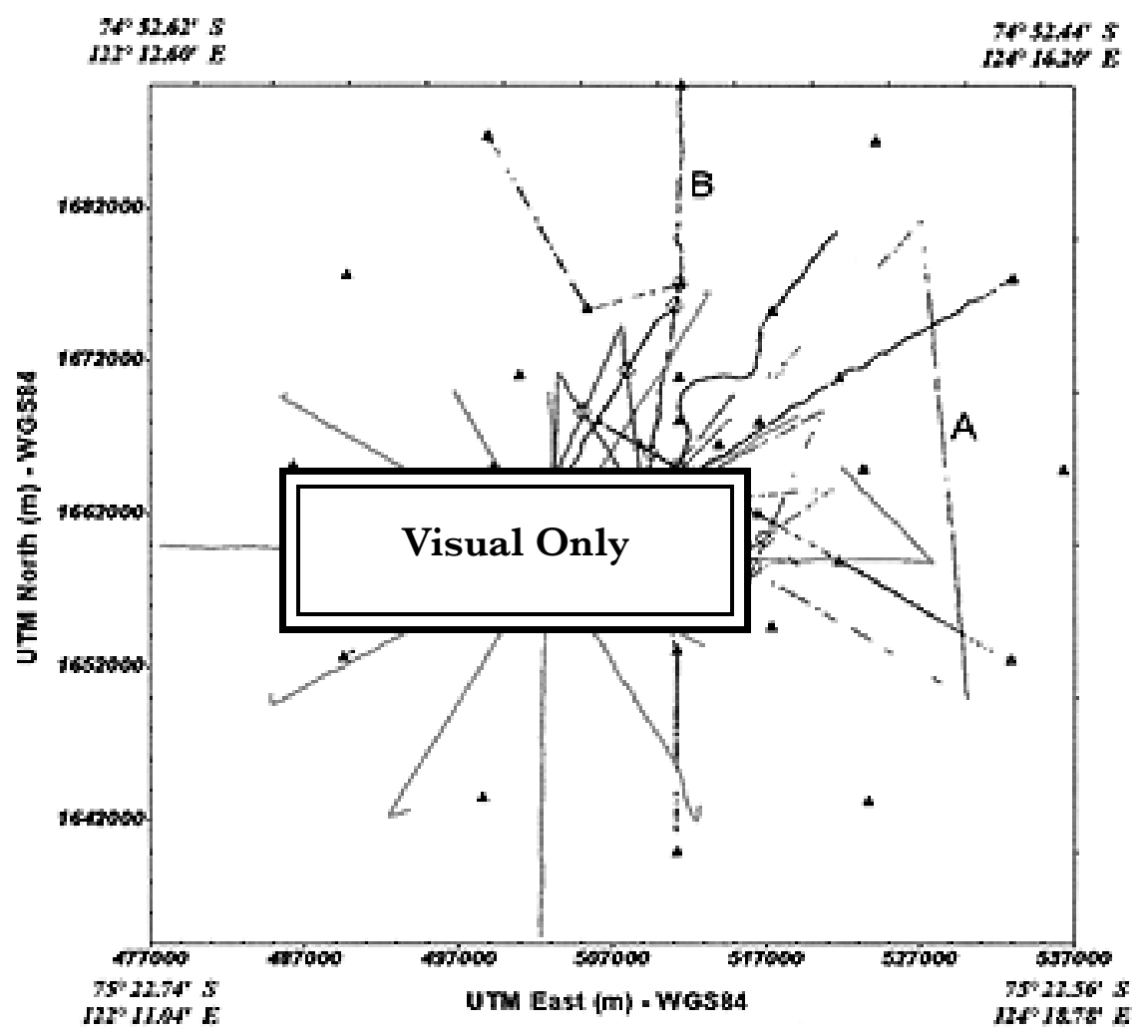

Fig. 1. The GPS surveys: 1993 kinematic survey, centered on the first approximate Dome C location (light blue); 1995 (A) kinematic survey (red); and 1995 (B) kinematic survey (blue), both centered on the new Dome Clocation. The triangles represent the points of the geodetic network. The circular symbols refer to the tested cross-overs between the different kinematic profiles. Coordinates are UTM from WGS84 ellipsoid: central meridian $123^{\circ}$ E. The corresponding WGS84 elipsoid coordinates of the four vertices relative to grid limits are shown.

length was about $2800 \mathrm{~km}$. The ground-based one was about $300 \mathrm{~km}$. Ice thickness over the whole area was calculated and the bedrock map constructed.

The following main bedrock features were detected:

(a) a plateau located in the central part of the area at a mean elevation corresponding to zero height-aboveelipsoid (HAE);

(b) a sharp ridge, near $125^{\circ} \mathrm{E}$, oriented south-north which is probably a tectonic feature. At $124.5^{\circ} \mathrm{E}$, an important trough, more than $500 \mathrm{~m}$ deep, yields a gradient up to 1000 metres per two kilometres; and

(c) a southern chain of mountains, oriented eastward, that probably diverts the flow coming from Vostok. The presence of a dome in this area is due to these two chains of mountains that influence the ice flow.

During the same campaign, a GPS geodetic strain network was established over an area of about $2000 \mathrm{~km}^{2}$ (Gandolfi and Vittuari, 1996). The network consisted of 37 points, distributed symmetrically on four concentric rings centered on the DORIS point (Fig. 1). Its geometry was simulated and analysed for optimization (Gubellini and others, 1996). $120 \mathrm{~mm}$ diameter aluminum stakes, $3 \mathrm{~m}$ long, inserted at least $2 \mathrm{~m}$ in the snow were adopted for the vertices.

Geodetic Trimble 4000 SSE and SSI L1/L2 receivers were used for the kinematic surveys, using high sampling rates to allow a detailed survey of the altimetric profiles. Pseudorange and carrier-phase data on both frequencies were stored by all receivers at every epoch. The recording time at stations was approximately $20 \mathrm{~min}$, and varied with respect to the distance between the master and rover receivers.
One or more GPS receivers were located as reference on the vertices of the geodetic strain network. The rover receivers, equipped with geodetic antennas, were installed on tracked vehicles. The reference stations were installed at the nearest vertices of the strain network to obtain the best kinematic GPS solution. The whole track length during the kinematic surveys was about $420 \mathrm{~km}$.

Static acquisitions (20-30 min long) were performed to compute the sets of initial integer-ambiguity parameters at the beginning of each kinematic survey. Other stops on particular tracts of the trajectories were planned to improve data processing. Comparison between the tracts of the kinematic trajectories and the points of the geodetic strain net allowed the accuracy to be checked.

\section{GPS DATA PROGESSING}

In equatorial and auroral areas, anomalies in the structure of the ionosphere cause a scintillation effect on the GPS signal. Such interference is particularly critical for high-accuracy GPS surveys because it creates cycle slips which make the integer estimation of phase ambiguities difficult. In other words, the signal-to-noise-ratio is degraded and an erroneous phase-cycle count may occur without apparent loss of lock (Viterbi, 1996; Ciraolo, 1994).

GPS data were preprocessed to check quality and identify problems. The use of multiple reference stations overcame particular problems regarding sets of static data affected by a large number of cycle slips on the L2 frequency. Kinematic data were processed using the static data of other receivers, simultaneously recording on the points of the geodetic network. 
The rover-receiver trajectory was computed afterwards, using the GPSurvey software (Trimble) and the Geotracer GPS software v. 2.25 developed by TerraSat. The package included an on-the-fly (OTF) algorithm, mainly designed for airborne GPS, that could recover the cycle slips (Landau, 1989; Euler and Landau, 1992).

The OTF algorithm included in the Geotracer program has several steps. A preliminary solution using the code modulated on the GPS frequencies was scanned to locate an optimal observation time-span for ambiguity resolution. This OTF ambiguity solution was performed on each selected interval using the following procedure: a solution using floatcarrier phase ambiguities for each satellite was estimated; estimated ambiguities were used to find a fixed solution; and the sets of ambiguities were statistically validated to guarantee the desired centimetric accuracy. Validated ambiguities were then fixed and propagated through the whole tracking time between losses of lock for each satellite.

Finally, the values of the relative-dilution-of-precision (RDOP) parameter relative to the processed data were analysed to overcome particular satellite-receiver geometries causing divergences in the double-difference system equations.

High values of the RDOP parameter can occur even with good positioning-dilution-of-precision (PDOP) values, considering that the RDOP value also depends on the relative position between the two GPS antennas:

$$
\mathrm{RDOP}=\sqrt{\frac{\operatorname{tr}\left(A^{\mathrm{T}} \sum_{\mathrm{dd}}^{-1} A\right)^{-1}}{\sigma_{0}^{2}}}
$$

where $A$ is the coefficient matrix of the linearized doubledifference system equations, $\sum_{\mathrm{dd}}^{-1}$ is the variance-covariance matrix of the phase measurements, and $\sigma_{0}^{2}$ is the weight unit variance.

The complanarity of visible satellites, some other particular satellite geometry, or rover-master direction, create a singularity in the double-difference system equation, with altered values of matrices suddenly increasing the resulting value of the RDOP parameter.

A forecast of the RDOP parameter often helps avoid problems of divergences in the solutions. Software that calculates its value for pseudo-range and phase measurements, starting from the satellite almanac, was developed at the University of Trieste (Cefalo and others, 1995).

Validation of profile portions was performed using the initial and final static aquisitions and comparison with the strain-net vertex coordinates.

The 1995 kinematic surveys are plotted in Figure 1 together with the 1993 kinematic trajectories (in Universal Transverse Mercator coordinates). The repeatability of GPS measurements was estimated from cross-over errors. The analysis was performed by comparing the ellipsoid height values at the intersections between the different trajectories, for every kinematic survey and for the two different sets of kinematic data. Table 2 summarizes the results of this analysis for the intersection points shown in Figure 1.

\section{ALTIMETRIC GONTOURING}

GPS tridimensional coordinates obtained from the two kinematic datasets and the points of the geodetic strain network were used to build the topography of the Dome $\mathrm{G}$ surface. Four common types of interpolators (kriging, triangulation, inverse distance to a power and minimum curvature) were

Table 2. Results of the analysis performed on the intersections between the different kinematic profiles in Figure 1. The values represent the differences in metres between the ellipsoid height values at crossovers

$$
\text { Height differences }
$$

$\mathrm{m}$

$\begin{array}{ll} & \text { Kinematic survey } A(\text { red }) \\ 0.02 & \\ 0.15 & \\ 0.12 & \\ 0.06 & \\ 0.10 & \\ 0.15 & \\ 0.05 & \\ & \quad \text { Kinematic survey B (blue) } \\ 0.10 & \\ 0.09 & \\ 0.15 & \\ 0.02 & \\ 0.15 & \\ & \text { Comparison between A and B surveys } \\ 0.07 & \\ 0.17 & \\ 0.06 & \\ 0.18 & \\ 0.20 & \end{array}$

considered a priori and tested using the 1995 kinematic GPS profiles as source data, and the GPS network as test points, in order to choose the best interpolation method. Several options were used for each interpolator, varying the shape and size of the search radius for each gridding technique; the anisotropy for searching, the power for the inverse distance ( 2 and 3 power were used), as well as the level of smoothing. Each parameter was changed leaving the others constant. The residuals were then calculated for each grid obtained on the GPS static points. The standard-deviation parameter of whole residuals was computed for each grid. Table 3 summarizes the best values obtained for each gridding technique analysed. Based on these analyses, the "triangulation" gridding technique was chosen. The contour levels were plotted every $0.25 \mathrm{~m}$ with highly smoothed contours. This was done in order to obtain a smoother topographic surface. From the kinematic GPS it is possible to show the roughness of the surface, particularly the shape of sastrugi

Table 3. Comparison between the statistical parameters of the best results obtained for each gridding interpolator, using the 1995 kinematic profiles as source data and the static GPS points of the geodetic network as test points

\begin{tabular}{ccc} 
Std dev. & Minimum & Maximum \\
$\mathrm{m}$ & $\mathrm{m}$ & $\mathrm{m}$ \\
& & \\
\hline 0.396 & -1.46 & 0.248 \\
0.194 & -0.366 & 0.647 \\
0.387 & -1.518 & 0.091 \\
0.658 & -2.539 & 0.235
\end{tabular}




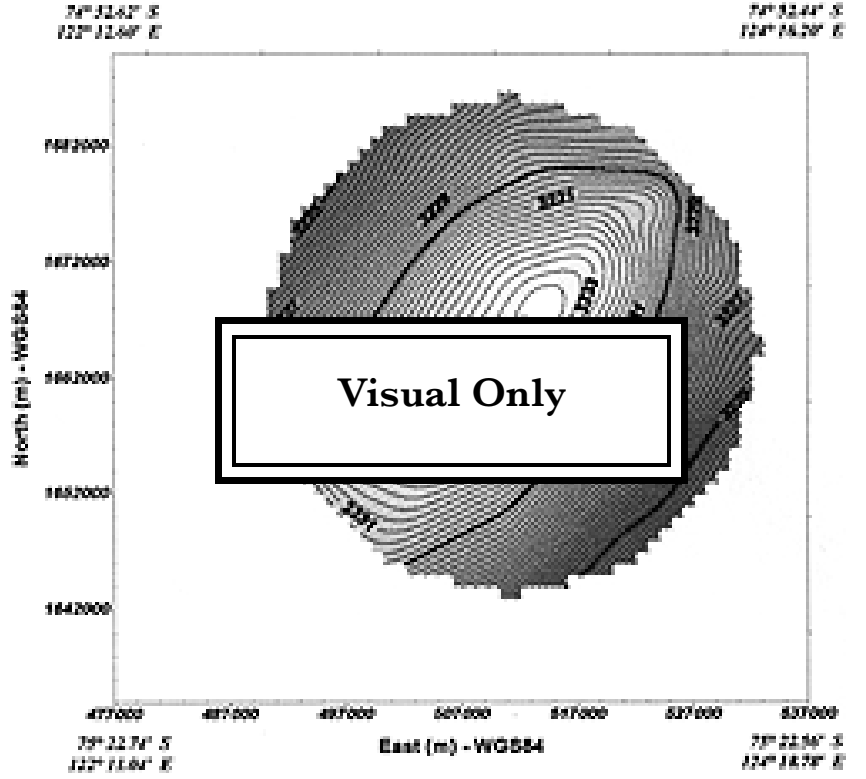

Fig. 2. Dome C topographic surface from 1995 GPS data using all kinematic ( $A$ and $B$ ) and static surveys (geodetic network). Contour interval is $0.25 \mathrm{~m}$.

features created by katabatic winds, but this is only true on the surveyed profiles. An extrapolation of this "high-frequency" component of the surface would not be realistic elsewhere. A contour interval of $0.25 \mathrm{~m}$ was thus adopted based on the tested accuracy of the GPS data. The resulting map is shown in Figure 2.

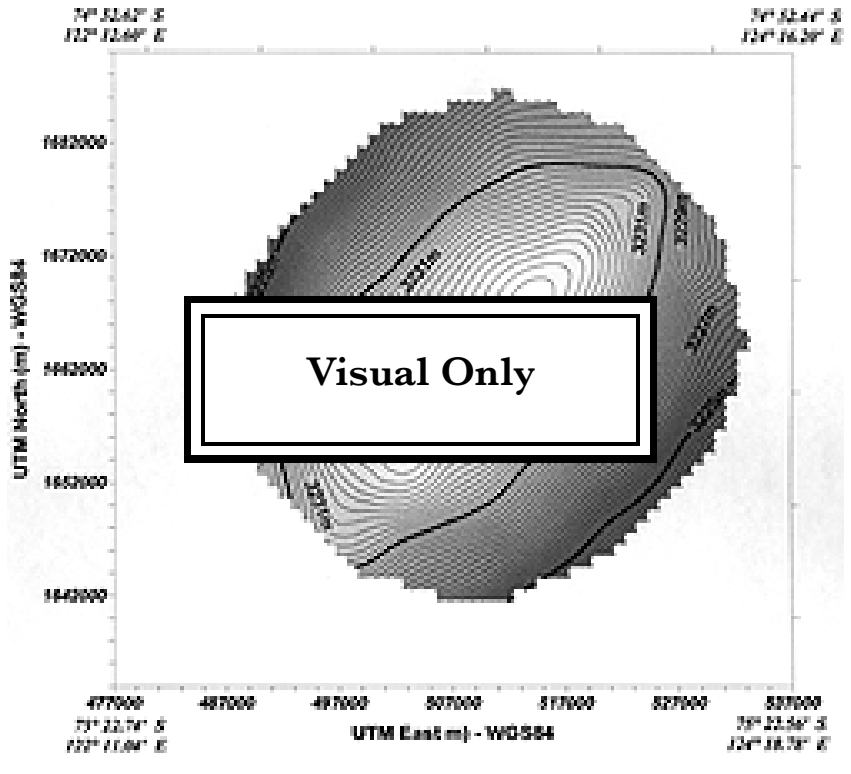

Fig. 3. The final surface map of Dome $C$ area obtained contouring all 1993 and 1995 GPS data. Contour interval is $0.25 \mathrm{~m}$.

The residuals between the grid obtained using 1995 GPS data and 1993 kinematic data were computed in order to test the range of height variations in the Dome $\mathrm{C}$ area between the two surveys. The values were in the range of accuracy of the 1995 grid. A new map was therefore drawn up using all the data (Fig. 3). The contour map (0.25 $\mathrm{m}$ interval) was

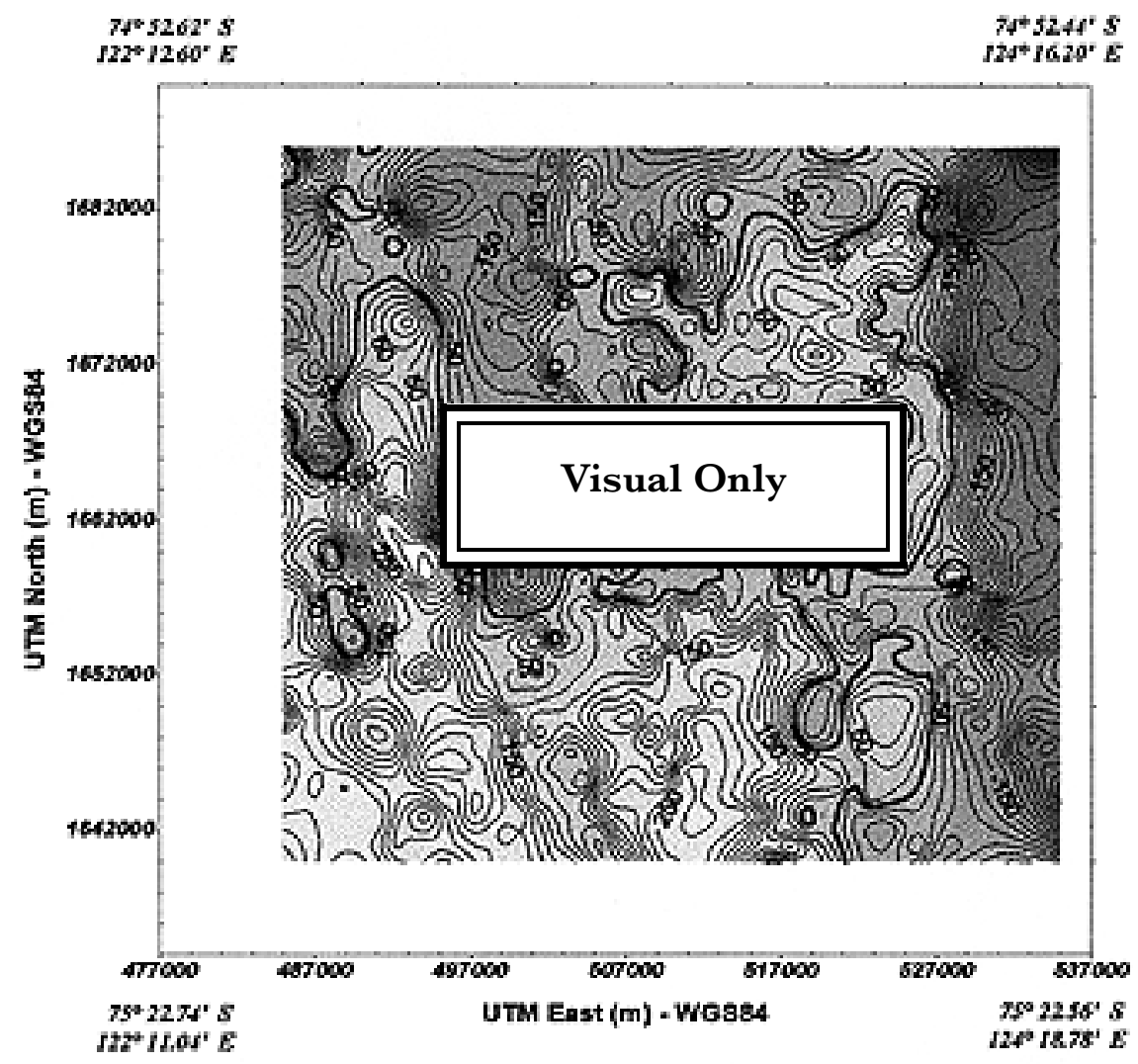

Fig. 4. Bedrock topography of Dome C area from radio-echo soundings. The asterisk identifies the Dome C location. Heights are WGS84 ellipsoid ones. Contour interval is $25 \mathrm{~m}$. 
computed inside the external perimeter of the geodetic strain network. The topographic surface was then used as reference for the bed topography obtained from groundbased and airborne radio-echo-sounding surveys. Figure 4 shows the bedrock topography of Dome $\mathrm{C}$ area. The topographic anomalies visible in the southwestern part of Figure 3 relate to the effects of the little ridge of the mountain chain, which acts like a barrier, and to ice fluxes coming from south, which can alter the features.

\section{GONGLUSIONS}

The 1993 kinematic GPS data and the 1995 static and kinematic data were used to map the topographic surface of the Dome Concordia area, with an accuracy in the range of $0.20 \mathrm{~m}$. This value also takes into account the tracked-vehicle penetration into the ice between one passage and the next, whose value was evaluated in the range of $0.10 \mathrm{~m}$. The resulting map can be considered as the Dome $\mathrm{C}$ topographic reference map for the 1995/96 austral summer.

The interferential kinematic GPS method is a quick and precise technique for surveying the topography of an area, and can synchronize and georeference data from different geophysical surveys. This technology gives accurate data that can be used alone, or in connection with other geophysical techniques, and is capable of covering larger areas, but requires a precise absolute calibration (i.e. ERS-1 radar altimeter).

The main advantages of the method are the high productivity and reliability of measurements, even in extreme environmental conditions. Comparison between different GPS techniques, characterized by different levels of precision, allows an internal validation of the results. Finally, the use of the contemporary French DORIS system allowed the whole GPS survey to be positioned into the adopted International Terrestrial Reference Frame (ITRF'92) system, and then into the WGS84 ellipsoid at centimetric accuracy.

\section{ACKNOWLEDGEMENTS}

This work is a contribution to the European Project for Ice Coring in Antarctica supported by the European Commission and co-ordinated by the European Science Foundation. We thank the national funding agencies and organizations in Belgium, Denmark, France, Germany, Italy, The Netherlands, Norway, Sweden, Switzerland and the United Kingdom for financial support.

\section{REFERENGES}

Brisset, L. and F. Rémy. 1996. Antarctic topography and kilometre-scale roughness derived from ERS-1 altimetry. Ann. Glaciol., 23, 374-381.

Cefalo, R., G. Manzoni and G. Skerl. 1995. Perspectives of soil movements by means of real time continuous kinematic GPS. In FMG95, 4th International Symposium on Field Measurements in Geomechanics, 10-12 April 1995, Bergamo, Italy. Proceedings. Padova, SGEditoriali, 527-533.

Cefalo, R., I. E. Tabacco and G. Manzoni. 1996. Processing of kinematic GPS trajectories at Dome C (Antarctica) and altimetry interpretations. In Unguendoli, M., ed. Reports on Surveying and Geodesy. Bologna, DISTART Ed. Nautilus. Università degli Studi di Bologna, 204-222.

Ciraolo, L. 1994. Ionosphere and GPS. In $13^{\circ}$ Convegno del Gruppo Nazionale di Geofisica della Terra Solida, 28-30 November 1994, Rome. Proceedings. Rome, ESAGRAFICA, 299-310.

Euler, H. I. and H. Landau. 1992. Fast GPS ambiguity resolution on-the-fly for real time applications. In 6th International Geodesy Symposium on Satellite Positioning, Columbus, Ohio. Proceedings. Vol. 2, 650-658.

Gandolfi, S. and L. Vittuari. 1996. Preliminary results of the first GPS strain net survey in Dome C area (Antarctica). In Unguendoli, M., ed. Reports on Surveying and Geodesy. Bologna, DISTART Ed. Nautilus. Università degli Studi di Bologna, 367-376.

Gubellini, R., F. Radicioni and A. Stoppini. 1996. Analysis and design of the "Dome C" (Antarctica) GPS strain control network. In Unguendoli, M., ed. Reports on Surveying and Geodesy. Bologna, DISTART Ed. Nautilus. Università degli Studi di Bologna, 15-32.

Landau, H. 1989. Precise kinematic GPS positioning. Bull. Géod., 63(1), 85-96.

Tabacco, I.E., A. Passerini, F. Corbelli and M. Gorman. 1998. Correspondence. Determination of the surface and bed topography at Dome $\mathrm{G}$, East Antarctica. 7. Glaciol., 44(146), 185-191.

Vincent, C. 1994. Project Concordia, glaciology at Dôme C. Plouzané, Institut Français pour la Recherche et la Technologie Polaires.

Viterbi, A.J. 1966. Principles of coherent communication. New York, McGraw-Hill. 